\title{
Erratum to: Impact of inflammatory state and metabolic control on responsiveness to dual antiplatelet therapy in type 2 diabetics after PCI: prognostic relevance of residual platelet aggregability in diabetics undergoing coronary interventions
}

\author{
Tobias Geisler $\cdot$ Karin Mueller • Simon Aichele $\cdot$ Boris Bigalke • \\ Konstantinos Stellos • Patrick Htun • Elena Ninci - Susanne Fateh-Moghadam • \\ Andreas E. May • Meinrad Gawaz
}

Published online: 4 August 2010

(C) Springer-Verlag 2010

Erratum to: Clin Res Cardiol

DOI 10.1007/s00392-010-0179-x

The original version of this article unfortunately contained a mistake.

The acknowledgment was missing and is given here:

T. Geisler is funded by the 'Atherothrombosis Research

Grant' from the European Society of Cardiology.

The online version of the original article can be found under doi:10.1007/s00392-010-0179-x.

T. Geisler $\cdot$ K. Mueller $\cdot$ S. Aichele $\cdot$ B. Bigalke

K. Stellos · P. Htun - E. Ninci - S. Fateh-Moghadam ·

A. E. May · M. Gawaz

Medizinische Klinik III,

Kardiologie und Kreislauferkrankungen,

Eberhard Karls Universität, Tübingen, Germany

T. Geisler $(\bowtie)$

Clinical Trials and Evaluation Unit, Royal Brompton Hospital,

Imperial College, London, UK

e-mail: t.geisler@rbht.nhs.uk; tobias.geisler@email.de 